Proc. of the Fourth International Conference on Advances in Social Science, Management and Human Behaviour - SMHB 2016. Copyright $(\subseteq$ Institute of Research Engineers and Doctors. All rights reserved.

ISBN: 978-1-63248-116-0 doi: 10.15224/ 978-1-63248-116-0-67

\title{
Risk analysis in the introduction of new technologies in Brazil by startups
}

\author{
Pedro Teberga, Fábio Lotti Oliva
}

\begin{abstract}
The volatility of technological innovation showcases the need for close risk control processes as a means to ensure viability in the process of launching new tech onto the Brazilian market by startups. The purpose of this work is to present a conceptual framework for the management of such risks, aiming at providing guidelines for the improvement of such process based mainly on the NPVR approach. The methodology relied on four comparative case studies that had their data collected via documents provided by the organizations and interviews with their main managers. The data analysis followed the model in [1], which allowed the condensation and data visualization; and drawing conclusions. Among the main results, there is the proposition of a deductive-inductive matrix for the management of risks and uncertainties in startups, which brings elements that provide the calculation of the net present value adjusted to the risk of developing a new product as well as a contribution to the level of risk management and maturity of the companies studied by setting up the Startup risk management Matrix
\end{abstract}

.Keywords: Risk management, new technologies, startup, NPVR for startups.

\section{INTRODUCTION}

A startup is a temporary organization in search of a repeatable, scalable and profitable business model [2]. In Brazil, it is increasingly common entrepreneurs to invest in startups to start a business that offers solutions to various sectors of the economy, such as health and education for instance. According to [3] though, theories of strategy, planning and market research do not apply to startups as these approaches are designed to already consolidated companies which operating history allows reasonable forecasting differing from the uncertain environment that startups normally operate in.

Startups are recognized, among other aspects, for its high risk and high failure rate, for usually not being selfsustaining, and for a work team with little experience [4]. All those aspects highlight the need for an effective and efficient management of uncertainty.

Pedro Teberga

School of Economics, Business and Accounting of the University of São Paulo

Brazil

Fábio Lotti Oliva

School of Economics, Business and Accounting of the University of São Paulo

Brazil
Therefore, considering the emergence of startups in the Brazilian organizational scenario and the importance of understanding risk management strategies that are oriented to launch new technologies, it was proposed the following general objective for this study: Analyze the process of managing risks in the introduction of products, processes or services by startups that operate in the Brazilian market.

To achieve this purpose, it was adopted the vision of the Net Present Value Risk-Adjusted (NPVR), or Valor Presente Líquido Ajustado ao Risco [5], and the perspective of the "Maturity Level in Enterprise Risk Management" [6] to propose conceptual categories.

The conceptual framework of the research was developed in deductive form and perfected from inductive data that emerged from the strategy of the case studies, which selected the launch of four products in the Brazilian market: the MercadoPago, GuiaBolso, Betalabs and Catarse. The cases were selected because they represent two relevant categories within the NPVR perspective.

Among the results, it is worth noting that the risks in the launch of a product by a startup are related to the product type, represented by the categories New Ventures, New categories, New platforms and New products, and also with the understanding of the technology, the market and the users to whom the product is intended to

\section{LITERATURE REVIEW}

Unlike a consolidated company, for which the market is well defined and the basis of competition is understood, startups work under hypotheses that are tested with customers for the formulation of facts [2]. In addition, startups have some limitations in some aspects, such as those related to resources and human capital. Thus, any bad decisions in understanding the market can result in serious consequences, or even your the end of the startup [7].

All organizations face uncertainty and the challenge of its managers is to determine when to accept them and define how these uncertainties can interfere with the effort to create value for stakeholders. Given the uncertain and unpredictable complexity, [8] propose two alternatives: learning by trial and error, and selectionism. Selectionism refers to conducting a number of solutions in parallel so that the best choice is selected later.

Trial and error requires learning flexibly and adjusting to new information that is obtained during the course of project implementation, ie planning for the next critical event or redesigning a posteriori, rather than planning everything in detail at the beginning. This is why we use the name "learning" instead of "planning" because each step depends on the learning that occurred in the previous step.

Complementary to these two actions, [9] defined the execution process given a select set of resources and by discovering the possible effects that can be created from these resources. According to the author, this approach is best 
Proc. of the Fourth International Conference on Advances in Social Science, Management and Human Behaviour - SMHB 2016. Copyright $(\subseteq$ Institute of Research Engineers and Doctors. All rights reserved.

ISBN: 978-1-63248-116-0 doi: 10.15224/ 978-1-63248-116-0-67

suited for environments with high levels of uncertainty, such as the early stages of a company or a market.

Is it also possible to relate the entrepreneurial action to the business model. The business model is more suitedto accommodate uncertain environments because unlike a traditional design, it requires less data and analysis.

[3] suggested that the business model is a way of articulating an opportunity aligned with the real needs of customers.

To assist in structuring the business model, there are a number of approaches in the literature, such as Canvas, proposed by [10].

This approach considers that a business model that consists of nine links: market segment, value proposition, distribution channels, customer relationships, sources of income, key activities, key partners and costs.

In a risk scenario for the investor, [11] proposed an approach that can make a less risky project. It is the methodology of a lean start-up, which advocates experimentation instead of elaborate planning, customer feedback over intuition, and interactive design unlike traditional development.

In addition to the aspects of Lean Startup, this article proposed the combination of the use of nPVR framework with the view of Maturity Level in Enterprise Risk Management (MLERM) in those organizations, understanding that this approach can effectively complement the management of risks and uncertainties.

\section{Framework NPVR}

In developing a new product, strategic risk has a greater relevance because it involves important points regarding the product acceptance. According to [6], the risks of a business can be of different natures and may have different degrees of importance for each agent. The business environment includes several organizations, and macro and microenvironmental forces. It is also important to consider that in these environments, different agents interact, namely: customers, competitors, suppliers and distributors.

Environmental forces in the microenvironment are expressed by the bargaining power, opportunism, innovation and strategy of their agents [6].

It is important to recognize which of these elements are for each startup, since they are not considered in view of the nPVR, although important in certain contexts. These risks make up the Maturity Level in Enterprise Risk Management (MLERM).

In this sense, [5] developed the conceptual framework, nPVR - net present value, which adjusted to the risk of developing a new product. nPVR is a model which provides quantitative tools that increase the Return on Investment (ROI), thus increasing the likelihood of a successful product. The framework provides advantages by analyzing

risk as compared to traditional models, such as decision trees and real options, which are complex and may require information not readily available at the beginning of the development process.

By focusing on some evaluation areas, the main development risks are exposed and predictability of new product development is amplified. The nPVR depends on the user experience and judgment to assess subjectively the relative risk. However, instead of requiring a probability estimate, the scores are scaled for high, medium and low.

Qualitative assessments can be easily converted into numerical values after a consensus. In nPVR model, this is done by allocating the more positive rating (high chance of success) to the value 5 and the more negative rating (low probability of success) to the value of 1 on a scale of 1 to 5 .

Using these assessments, decision makers can compare the value of the Risk Adjusted Net Present (nPVR) with the traditional Net Present Value. This allows managers to understand the part of a NPV proposal that is at risk quickly and consistently,while focusing on key factors.

For this, [5] established two divisions of risks necessary for the development of its methodology and development to determine the risks and their ratings: the product category; and technical category, market and user. Along these lines, the division of product category has four items:

a) New Ventures - are 'new to the world', which represent the first of its kind and require the creation of a whole new market.

b) New categories - are 'new to the company' and include new product lines, which target an established market in which the company does not currently compete.

c) New platforms - are often additions to existing product lines. Platforms create the basis for future derivative products, providing better market knowledge and know-how of manufacturing.

d) New products - are derived from improvements and revisions of existing products, including cost reductions.

After researching 200 companies, [5] drew up a framework and proposed the categories with the most significant risks: the market, technical or user - in each of the categories, which are expressed in Table 1:

Table 1. Distribution of risks by category. [5] free translation

\begin{tabular}{|c|c|c|c|c|}
\hline & $\begin{array}{c}\text { Market Risk } \\
\text { Weight (M) }\end{array}$ & $\begin{array}{c}\text { Techaical Risk } \\
\text { Weight (T) }\end{array}$ & $\begin{array}{c}\text { Llser Risk } \\
\text { Weight (U) }\end{array}$ & Total \\
\hline New Venture & 0.45 & 0.1 & 0.45 & 1 \\
\hline New Categocx & 0.4 & 0.2 & 0.4 & 1 \\
\hline New Platform & 0.35 & 0.35 & 0.3 & 1 \\
\hline $\begin{array}{c}\text { New Derixatixs } \\
\text { Product }\end{array}$ & 0.3 & 0.6 & 0.1 & 1 \\
\hline
\end{tabular}


Proc. of the Fourth International Conference on Advances in Social Science, Management and Human Behaviour - SMHB 2016.

Copyright (C) Institute of Research Engineers and Doctors. All rights reserved.

ISBN: 978-1-63248-116-0 doi: 10.15224/ 978-1-63248-116-0-67

In addition to the division by category, the author defines the market, technological and user risks.

\section{a) Market Risks}

The real disruptive innovation happens in environments where $\mathrm{t}$ he final product and its value proposition, price, marketing, sales channels, and more importantly, your customers are, at best, assumptions [12]

Thus, the market risk refers to any required value chain element for any new product needed to reach your prospective clients. This includes factors such as skills sales force, distribution channels, manufacturing capabilities and customer support.

Each element should be understood and evaluated. In addition, success will be influenced by the company presence in the target market segment [5].

b) Technical Risk Assessment

Technical risks are related to the product and the company's development capabilities. Innovation risks must be evaluated not only in terms of the technology itself, but also the degree to which technology is integrated into existing processes of product development. Skills assessment should include the development team and its support for program management.

\section{c)User Risk Assessment}

The risk of the user is determined by the likelihood that the company is developing a product that will be valued by the market. The User Risk Assessment focuses on the degree to which we understand the way the user interacts with the product and the degree to which the design and performance specifications are known.

From the data collected by the present model, the nPVR is calculated according to Davis (2002) as follows:

$\mathrm{NPVR}=(\mathrm{aM}+\mathrm{bM}+\mathrm{cT}+\mathrm{dT}+\mathrm{eU}+\mathrm{fU}) / 10) \quad \mathrm{x}$ Net Present Value

In this case, $\mathrm{a}, \mathrm{b}, \mathrm{c}, \mathrm{d}, \mathrm{e}$, and $\mathrm{f}$ refer to the following evaluations: the value chain, the interaction capabilities, innovation, market segment and specifications capabilities, respectively. Each of these items should be ranked on a scale of 1 to 5 . Risks are weighted as $\mathrm{M}$ (market), $\mathrm{T}$ (technical) and $U$ (user) are chosen according to the product category.

It was concluded that the nPVR model provides, for example, insights into researching the potential user and how this can affect the success of a product. Researching the user at the beginning of the development cycle should improve the risk assessment of interaction and change the odds of success in this area, from the bottom up.

In fact, there is no guarantee that the product will be successful in absolute terms. But when comparing proposals within a category, those with higher scores are more likely to succeed than those with low scores.

\section{RESEARCH METHOD}

The methodological path of this research was guided by the research question and their goal. [13] established that the research design is the logic that combines empirical data with initial research questions of the study and, ultimately, to its conclusions. The approach chosen to answer the question was qualitative [14]. From the point of view of its objectives, the research is characterized as exploratory.

In terms of research strategies, we opted for the multiple case study. According to [13], the case study is the preferred method when trying to study the "how" and "why" of an event.

The purpose of using multiple cases in this study was to allow us to compare the product launch in different startups. Therefore, we could identify similarities and differences between the cases and clearly see the relationship between the context and each product.. The unit of analysis was the process of launching a new product. The selection of cases was based on dimensions that were considered important to the search results as a whole, since they have been chosen as four significant cases in the ecosystem of Brazilian startups.

The data was collected through interviews with key executives involved in the product launch, as well as documents related to each case. In this way, we use three sources of evidence for the collection of data from this research: documentation, records taken from the company's web pages and semi-structured interviews with an executive from each of the companies studied.

In MercadoPago (Case 01), the respondent was the General Director of the company. In GuiaBolso (Case 02), Catarse (Case 03) and BetaLabs (Case 04), respondents were the founders and co-presidents.

The data analysis model was based on [1] and contained the condensed versions of data elements; data visualization; and the preparation and verification of conclusions, which were used iteratively and simultaneously. The data was condensed at the first and second levels, allowing open and interpretive coding with the support of family codes deductively proposed from the theoretical framework of this research and also those who emerged inductively. The codes were also applied to a second researcher and then validated together.

To classify the nPVR of each case,magnitude coding technique, proposed by [5] was used. The coding magnitude is a resource indicated by [1] in order to enhance features within the description of the qualitative research. 
Proc. of the Fourth International Conference on Advances in Social Science, Management and Human Behaviour - SMHB 2016. Copyright (C) Institute of Research Engineers and Doctors. All rights reserved.

ISBN: 978-1-63248-116-0 doi: 10.15224/ 978-1-63248-116-0-67

\section{RESULTS AND DISCUSSIONS}

Data was condensed by coding the first and second levels, with reference to the proposed coding aspects of the deductive way.

From the combination of deductive and inductive aspects, the data was analyzed, described and displayed through tables and textual descriptions. Finally, a model was generated to assist future startups in launching new technologies in the Brazilian market, which is shown in Figure 2 below:

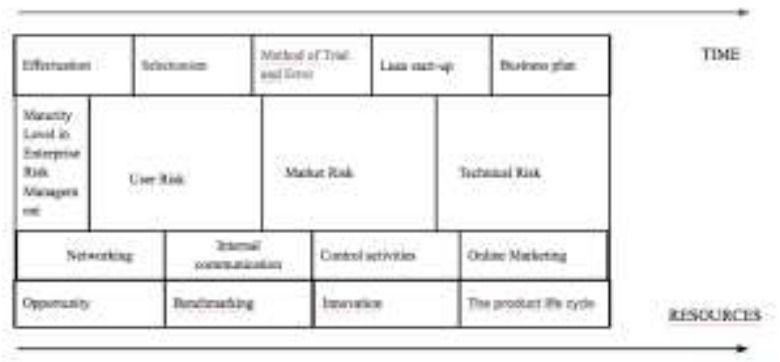

Figure 1. Risk Management Matrix.

Each item in the boot Risk Management Matrix was inserted according to an order defined in this research. This order considered the factors of time and resources as limiting the launch and development of a new technology. The bottom line of the matrix describes different aspects related to the product. These aspects evolve from left to right and are correlated with time. The more mature a product is, the more aspects from the right are observed.

The second line relates to communication. In the same way, the product also has a development from left to right. The central column is the risk analysis and the top line shows the entrepreneurial actions regarding uncertainty. Again, the evolution occurs from left to right, and is connected with the time and resources that the company has. The more the company has characteristics from the extreme right, the lower the associated risks will be.

Comparing the companies that are analyzed by the points discussed in this study, it can be observed that the Catarse is the closest startup to following the boostrapping model, which is when the partners use only their own resources, without investment funds or an accelerator. MercadoPago is positioned at the other end, because it originated in an ecosystem "MercadoLibre", which is a consolidated company in the market, with a capital structure and mature human resources system.

The BetaLabs can be considered the nearest second to the boostrapping the model because it also has received the investment fund contributions, however, it has a more organized management model. Finally the GuiaBolso approaches the MercadoPago, by also have investment funds and mentors who have helped the company to professionalize more quickly, although they do not have a validated business model yet and are not inserted in a business ecosystem like the MercadoPago.
Despite these differences, the uncertain environment and the generation of an innovation from an opportunity, the application of Trial-and-error learning model and Lean Startup are perceived in all cases.

By analyzing the perspective of the entrepreneurial activities in relation to uncertainty, it is clear that the more a startup has a model similar to the MercadoPago, it can be seen that most planning happens before making investment decisions. Compared to this point, MercadoPago was the plan of development for each project implemented, which enables a better evaluation of performance. $\mathrm{n}$ addition, the communication factor during project management is relevant, as well as online marketing for relationship with the clients.

At the other end, Catarse led strategic processes in a less structured manner and was did not adopt a business plan. According to the respondent, the partners had only a sheet of paper which reflects the model agents, but without a more thorough evaluation of each element of a business plan. Furthermore, in relation to the monitoring of implementation of activities in the early work on Catharsis it was remote which led to difficulty in control and reduction of decisionmaking agility.

Time devoted to planning is also a small factor in companies like Catarse, that had evolved for years without an organizational chart and performance measurement tools. Absence of resources, however, can not be a factor which rules out the possibility of planning, which is evidenced by the case of BetaLabs that have though also not received investments, structured a robust strategic plan.

Notoriously, with time, startups tend to evolve to communication processes maturity and entrepreneurial actions become more structured.

Regarding the generation of innovation, it is noted that the four companies studied occurred benchmarking with foreign companies, which may be a reflection of the early stage of technological entrepreneurship in Brazil, considering the fact that copy tends to be less complex and involves less risk that the generation and validation of the model itself. However, it is noted that "tropicalize a" foreign model leads, in most cases, improvements in the original model. For example, the Brazilian market requires the availability of bank payment for payment systems like MercadoPago, which does not make sense for the business model of Paypal, a company similar to MercadoPago, based in the United States. That is, the marketing strategies, distribution channels, customer segments, form of interaction with the market and other variables are items to be examined and rethought, can not simply be 'cloned'.

Also with respect to the product, there are two extremes can be observed: in the case of BetaLabs, wherein the first launched had less than $50 \%$ of the final product; and in the case of GuiaBolso, wherein the first release already has a next version of the current. However, in all cases the evolution of the product was perceived and sought to meet the demands of users, following the philosophy of Lean Startup. 
Proc. of the Fourth International Conference on Advances in Social Science, Management and Human Behaviour - SMHB 2016. Copyright (C) Institute of Research Engineers and Doctors. All rights reserved.

ISBN: 978-1-63248-116-0 doi: 10.15224/ 978-1-63248-116-0-67

\section{CONCLUSIONS AND FUTURE WORK}

Based on these results, it is concluded that the main risks of the introduction of new technologies in the market are the technical, market and user risks, mentioned in NPVR vision. Complementary to these risks, there are other approached by Maturity Level in Enterprise Risk Management [6].

Regarding the degree of exposure to risks of these startups, it was possible to calculate them using the NPVR formula that considers the assessment of the value chain, market segment, innovation, interaction and specification abilities, and the weights $\mathrm{M}$ (Market) T (Technical) and U (User) that are chosen according to the product category.

From the point of view of risk management, the following entrepreneurial activities were proposed: selectionism, trialand-error learning, effectuation, business model and NPVR theory.

As additional contributions to the research question there was a correlation between the positive results for the business with communication, to both internal and external audiences.

Summarizing, the main contributions of this study are:

-Validation of NPVR formula for calculating the risk of each business case;

-Verification of the risks to which the startups are exposed;

-Development of an approach to uncertainty and risk;

The Risk management matrix framework provides a guide to the entrepreneurial action, especially related to the creation and management of an innovative business. The process of connecting uncertainties can help entrepreneurs to create and capture value from the uncertainties solution.

By studying this matrix the entrepreneur can see the actual stage of his business and have a guide to make it viable more quickly, through the investment in communication, for example.

This work has significant limitations. The first is the generalizability of the results, impossible since the methodological approach (case studies) does not allow generalization.

It will require future research to further develop the approach to Risk management matrix, to validate it in more startups and improve the results.

\section{ACKNOWLEDGMENT}

Faculdade de Economia, Administração e Contabilidade - FEA

Universidade de São Paulo - USP

Fundação Instituto de Administração - FIA

\section{REFERENCES}

[1] Miles, M. B., Huberman, M., \& Saldaña, J. (2014) Qualitative data analysis: a methods sourcebook. (3rd ed.)
Thousand Oaks, CA: SAGE Publications, Inc.

[2] Blank, S., \& Dorf, B. (2012).The startup owner's manual:The Step-by-step Guide for Building a Great Company Malta, MT: K\&S Ranch.

[3] Ries, E. (2011). The lean startup: How today's entrepreneurs use continuous innovation to create radically successful businesses. New York: Crown Books.

[4] Giardino, C., Unterkalmsteiner, M., Paternoster, N., Gorschek, T., \& Abrahamsson, P. (2014). What do we know about software development in startups? Software, IEEE, 31(5),28-32.

doi:doi.ieeecomputersociety.org/10.1109/MS.2014.129

[5] Davis, C. R. (2002). Calculated risk: A framework for evaluating product development. MIT Sloan Management Review, 43(4), 71-77.

[6] Oliva, F. L. (2016). A maturity model for enterprise risk management. International Journal of Production Economics, 173(1), 66-79. doi:10.1016/j.ijpe.2015.12.007

[7] Christensen, C. (2013). The innovator's dilemma: when new technologies cause great firms to fail. Boston, MA: Harvard Business Review Press.

[8] Sommer, S. C., \& Loch, C. H. (2004). Selectionism and learning in projects with complexity and unforeseeable uncertainty. Management Science, 50(10), 1334-1347.

[9] Sarasvathy, S. D. (2001). Causation and effectuation: Toward a theoretical shift from economic inevitability to entrepreneurial contingency. Academy of Management Review, 26(2), 243-263. doi: 10.5465/AMR.2001.4378020

[10] Pigneur, Y., \& Ostenwalder, A. (2010). Business Model Generation A Handbook for Visionaries, Game Changers, and Challengers. Hoboken, NJ: John Wiley \& Sons Inc.

[11] Blank, S. (2013). Why the lean start-up changes everything. Harvard Business Review, 91(5), 63-72.

[12] Cooper, B., \& Vlaskovits, P. (2013). The lean entrepreneur: How visionaries create products, innovate with new ventures, and disrupt markets. San Francisco, CA: John Wiley \& Sons.

[13] Yin, R. K. (2015) Estudo de caso: planejamento e métodos (5 ed.) Porto Alegre: Bookman.

[14] Richardson, R. J. (1999). Pesquisa Social: Métodos e Técnicas. (3 ed. revista e ampliada). São Paulo: Atlas 